\title{
The opposite roles of PAS- 5 and Galectin-1 in immune response during the early infection of Angiostrongylus cantonensis
}

\author{
Lan-Zhu Yann ${ }^{1,2}$, Xiao-Meng Shi', Yan-Wen Zu' , Yuan-Yuan Shen ${ }^{3}$, Xi-Xi Chen ${ }^{4}$, Meng-Jing Zhao ${ }^{4}$, Xing-Pan Li', \\ Bao-Long Yan $^{1}$ and Hui-Cong Huang ${ }^{1 *}$
}

\begin{abstract}
Background: Angiostrongy/us cantonensis is a human zoonotic nematode parasite. Our previous studies found that PAS-5 and Galectin-1 (Gal-1) proteins of A. cantonensis could be strongly recognized by sera from mice infected with $A$. cantonensis. In this study, we further evaluated the potential roles of these two proteins in the induction of immune response in mice.

Methods: Mice were immunized with recombinant PAS-5 or Gal-1 and then challenged with 30 infective $A$. cantonensis larvae following the last immunization. We then examined the infected mice for changes in serum antibodies and cytokines by ELISA, CD4 ${ }^{+} \mathrm{T}$ cells and $\mathrm{CD} 4^{+} \mathrm{CD} 25^{+} \mathrm{FoxP}^{+}$regulatory $\mathrm{T}$ cells (Tregs) by flow cytometry, and tissue damage severity by hematoxylin-eosin (H\&E) staining.

Results: Compared with control mice, the PAS-5-immunized mice exhibited increased levels of serum antibodies and cytokines (except for IL-10) at different time points post-infection. PAS-5 immunization promoted significant proliferation of $\mathrm{CD}^{+} \mathrm{T}$ cells, and caused more damage in the brain tissue. Vaccination with Gal-1 inhibited the production of antibodies (except for IgG1) and IFN- - , but promoted the expression of IL-4 and IL-10. Gal-1 immunization results in significant increases in the levels of $\mathrm{CD} 4^{+} \mathrm{CD} 25^{+} \mathrm{FoxP}^{+}$Tregs, and mild inflammatory changes.

Conclusions: Taken together, our findings show that PAS- 5 enhances, but Gal-1 inhibits the immune response in the early stage of A. cantonensis infections.
\end{abstract}

Keywords: Angiostrongylus cantonensis, Early infection, PAS-5, Galectin-1, Immune response

\section{Background}

Angiostrongylus cantonensis, also known as rat lungworm, is a parasitic nematode that can cause zoonotic infections $[1,2]$. This species requires both intermediate host (slugs, snails and other mollusks) and definitive host (rats and other rodents) for completing the life-cycle. The first-stage larvae (L1) mainly exist in the feces of definitive hosts and develop into the infective third-stage larvae (L3) in the intermediate hosts. In definitive hosts, L3 migrate to the central nervous system (CNS) and develop into the fourth- and the fifth-stage larvae (L4 and L5). The L5 then migrate to the

\footnotetext{
* Correspondence: hhc@wmu.edu.cn

${ }^{1}$ Department of Parasitology, School of Basic Medical Sciences, Wenzhou Medical University, Wenzhou, Zhejiang 325035, People's Republic of China Full list of author information is available at the end of the article
}

pulmonary artery and heart of the definitive hosts via the circulatory system, where they develop into adult nematodes [2-4]. Humans, despite being unsuitable hosts, can become infected by drinking/eating water/ food contaminated by L3 of $A$. cantonensis, leading to eosinophilic meningitis, eosinophilic encephalitis [3-5], and ocular angiostrongyliasis [6]. Angiostrongylus cantonensis and angiostrongyliasis have been extensively studied, but the underlying pathogenic mechanisms are still largely unknown [7-9].

Previously, by utilizing two-dimensional gel electrophoresis (2-DIGE) and mass spectrometry (MS), we found that several interesting proteins of $A$. cantonensis, including Gal-1 and PAS-5, could be strongly recognized by sera from mice infected with $A$. cantonensis $[3,4,10]$. PAS- 5 is $\alpha 5$ proteasomal subunit and plays a major role

(c) The Author(s). 2018 Open Access This article is distributed under the terms of the Creative Commons Attribution 4.0 International License (http://creativecommons.org/licenses/by/4.0/), which permits unrestricted use, distribution, and 
in inducing host immune response [11]. The proteasomes of parasites may alter the morphology of cells within the host, remove damaged and defunct proteins, and execute other functions to participate in the immune response [12]. Galectins are involved in various physiological and pathological processes, including RNA transcription, cell adhesion, cell apoptosis and immune regulation $[3,4,13]$. Of all galectin members, the most studied is Gal-1, which has been found to be involved in the regulation of the immune response [14]. We here evaluate the effects of PAS- 5 and Gal- 1 on host immune response in the early stage of $A$. cantonensis infection. We screened the infected mice for changes in serum antibodies, cytokines, and $\mathrm{CD}_{4}^{+} \mathrm{T}$ cells and $\mathrm{CD} 4^{+} \mathrm{CD} 25^{+} \mathrm{FoxP}^{+}$Tregs, as well as for differences in tissue damage severity. The results of our study provide insight into the pathogenic mechanism of this organism, and could comprise a theoretical basis for treating angiostrongyliasis.

\section{Methods}

\section{Gene cloning and expression}

The total RNA of $A$. cantonensis was extracted using Trizol reagent and reversely transcribed into cDNA. The full-length open reading frames (ORFs) of PAS-5 and Gal-1 were amplified by PCR using following primer pairs. PAS-5: PAS-5-Forward, 5'-GT CATATG TTT CTA ACG CGA AGT G-3', and PAS-5-Reverse, 5'-CG TCTAGA ATG ATG ATG ATG ATG ATG CAA ACT TGA AAT GAC AAC G-3'; Gal-1: Gal-1-Forward, 5'-CG GGAT CC CAT CAT CAT CAT CAT CAT ATG TCG TCT CCT CCA-3', and Gal-1-Reverse, 5'-CT TCTAGA CTA CTG AAT TTG AAT GCC GGT-3'. The 6xHis tag-encoding sequences are marked in bold. The ORFs of PAS-5 and Gal-1 were then subcloned into pColdIII to generate plasmids pColdIII-PAS-5 and pColdIII-Gal-1, respectively. The resulted plasmids were transformed into $E$. coli BL21, and the recombinant proteins (rPAS-5 and rGal-1) were expressed by IPTG induction and purified with NI-NTA beads.

\section{Animals and parasites}

Pomacea canaliculata, the intermediate host of A. cantonensis, was supplied by a peasant household on a private property in Cangnan County, Wenzhou City, Zhejiang Province, China, and consent was obtained from this household to use the intermediate host for our study. Upon receipt, several $P$. canaliculata snails were selected at random for dissection and microscopic analysis to ensure that they were not infected with $A$. cantonensis or any other species of worm. After this confirmatory analysis, the remaining snails were simultaneously infected with $\mathrm{L} 1$ of $A$. cantonensis to ensure that all resulting L3 were of the same origin. The C57BL/6 female mice (5-6 weeks-old, grade SPF) were supplied by the Laboratory Animal Center of Wenzhou Medical University (Zhejiang, China). Laboratory reared Sprague-Dawley rats that were infected with L3. The L3 were obtained as previously described $[3,4]$.

\section{Immunity and infection}

Seventy-two mice were randomly and equally divided into three groups: group 1, mice immunized with rPAS-5 plus adjuvant; group 2, mice immunized with rGal-1 plus adjuvant; and group 3, mice immunized with PBS plus adjuvant. The mice were immunized using the procedure shown in Table 1. For the first round of immunization, Freund's complete adjuvant (Sigma-Aldrich, St. Louis, MO, USA) was used, while Freund's incomplete adjuvant (Sigma-Aldrich) was used for the second and the third rounds. The recombinant protein plus adjuvant compound was emulsified by pumping it through a syringe repeatedly until a "water-in-oil" state was achieved. The immunization was performed thrice at one-week intervals.

One week after the last immunization, mice were challenged with $30 \mathrm{~L} 3$ by oral inoculation, and then screened for changes in serum antibodies, cytokines, and $\mathrm{CD} 4^{+} \mathrm{T}$ cells and $\mathrm{CD}^{+}{ }^{+} \mathrm{CD} 25^{+} \mathrm{FoxP}^{+}$Tregs, and for tissue damage severity at weeks 0 (before infection), 1, 2 and 3 .

\section{Evaluation of humoral immune responses by ELISA}

Serum levels of total IgG, IgG1, IgG2a and IgE were determined at different time points by ELISA analysis (eBioscience, San Diego, CA, USA) according to the manufacturer's instructions. Briefly, microtiter plates were coated with capture antibodies diluted in coating buffer (1:250) overnight at $4{ }^{\circ} \mathrm{C}$, and blocked with $200 \mu \mathrm{l}$ blocking buffer at $37^{\circ} \mathrm{C}$ for $2 \mathrm{~h}$. Then, $100 \mu \mathrm{l}$ of serum or standards were added, followed by $50 \mu \mathrm{l}$ of HRP-conjugated detection antibody (1:250). After incubation for $3 \mathrm{~h}, 100 \mu \mathrm{l}$ of tetramethylbenzidine substrate solution was added, and the reaction was subsequently stopped with addition of $100 \mu \mathrm{l}$ of stop solution. Lastly, the absorbance of each well at $450 \mathrm{~nm}$ was measured using a plate reader, a standard curve was established according to the OD values, and antibody concentrations were calculated. All samples were assayed in triplicate.

\section{Cytokine measurements}

To observe the influence of PAS-5 and Gal-1 on cellular immunity, we measured the levels of cytokine production splenic cells upon treatment with each protein in vitro. First, the spleens of immunized and control mice were removed. Splenic cells were then harvested by grinding of the splenic tissues, centrifuging, $\mathrm{RBC}$ cracking, and centrifuging again. The resulting cell pellets were suspended in Dulbecco's modified Eagle's medium (DMEM) (Gibco, Grand 
Table 1 Experimental protocol: procedure for immunization of mice against $A$. cantonensis

\begin{tabular}{|c|c|c|c|c|}
\hline Day & Injection & Group 1 & Group 2 & Group 3 \\
\hline$\overline{0}$ & First & $100 \mu \mathrm{g}$ rPAS-5/mouse + adjuvant & $100 \mu \mathrm{g} \mathrm{rGal-1/mouse} \mathrm{+} \mathrm{adjuvant}$ & PBS + adjuvant \\
\hline 7 & Second & $50 \mu \mathrm{g} \mathrm{rPAS}-5 /$ mouse + adjuvant & 50 mg rGal-1/mouse + adjuvant & PBS + adjuvant \\
\hline 14 & Third & $50 \mu \mathrm{g} \mathrm{rPAS}-5 /$ mouse + adjuvant & $50 \mu \mathrm{g} \mathrm{rGal-1/mouse}+$ adjuvant & PBS + adjuvant \\
\hline 21 & \multicolumn{4}{|c|}{ Sacrifice and collect the samples ( 0 weeks before infection) } \\
\hline \multicolumn{5}{|c|}{ Challenge with $30 \mathrm{~A}$. cantonensis larvae/mouse } \\
\hline 28 & \multicolumn{4}{|c|}{ Sacrifice and collect the samples (1 week after infection) } \\
\hline 35 & \multicolumn{4}{|c|}{ Sacrifice and collect the samples (2 weeks after infection) } \\
\hline 42 & \multicolumn{4}{|c|}{ Sacrifice and collect the samples ( 3 weeks after infection) } \\
\hline
\end{tabular}

Island, NY, USA) and filtered with strainer mesh. Aliquots of the suspensions were then subjected to cultivation $\left(1 \times 10^{6}\right.$ cells $\left./ \mathrm{ml}\right)$ and flow cytometry analysis $\left(1.5 \times 10^{7}\right.$ cells $\left./ \mathrm{ml}\right)$. Splenic cells cultivated in 96-well plates were stimulated with PAS-5 (100 ng/ml) or Gal-1 $(25 \mathrm{ng} / \mathrm{ml})$ at $37{ }^{\circ} \mathrm{C}$ for $72 \mathrm{~h}$ in a humidified $5 \% \mathrm{CO}_{2}$ atmosphere. Supernatants were then collected, and the levels of IFN- $\gamma$, IL-4, IL-5 and IL-10 were measured by ELISA analysis (BD Biosciences, San Diego, CA, USA). Cells stimulated with concanavalin A (ConA,
Sigma-Aldrich) and PBS were used as positive and negative controls, respectively. The absorbance of each plate was read at $450 \mathrm{~nm}$, and a standard curve was established. All samples were assayed in triplicate.

\section{Flow cytometry}

Splenic cells were blocked with FACS blocking buffer for $30 \mathrm{~min}$, then incubated with anti-CD4-FITC, and anti-CD25-APC antibodies (BD Biosciences) for $30 \mathrm{~min}$ on ice. Samples were treated with fixation/permeabilization

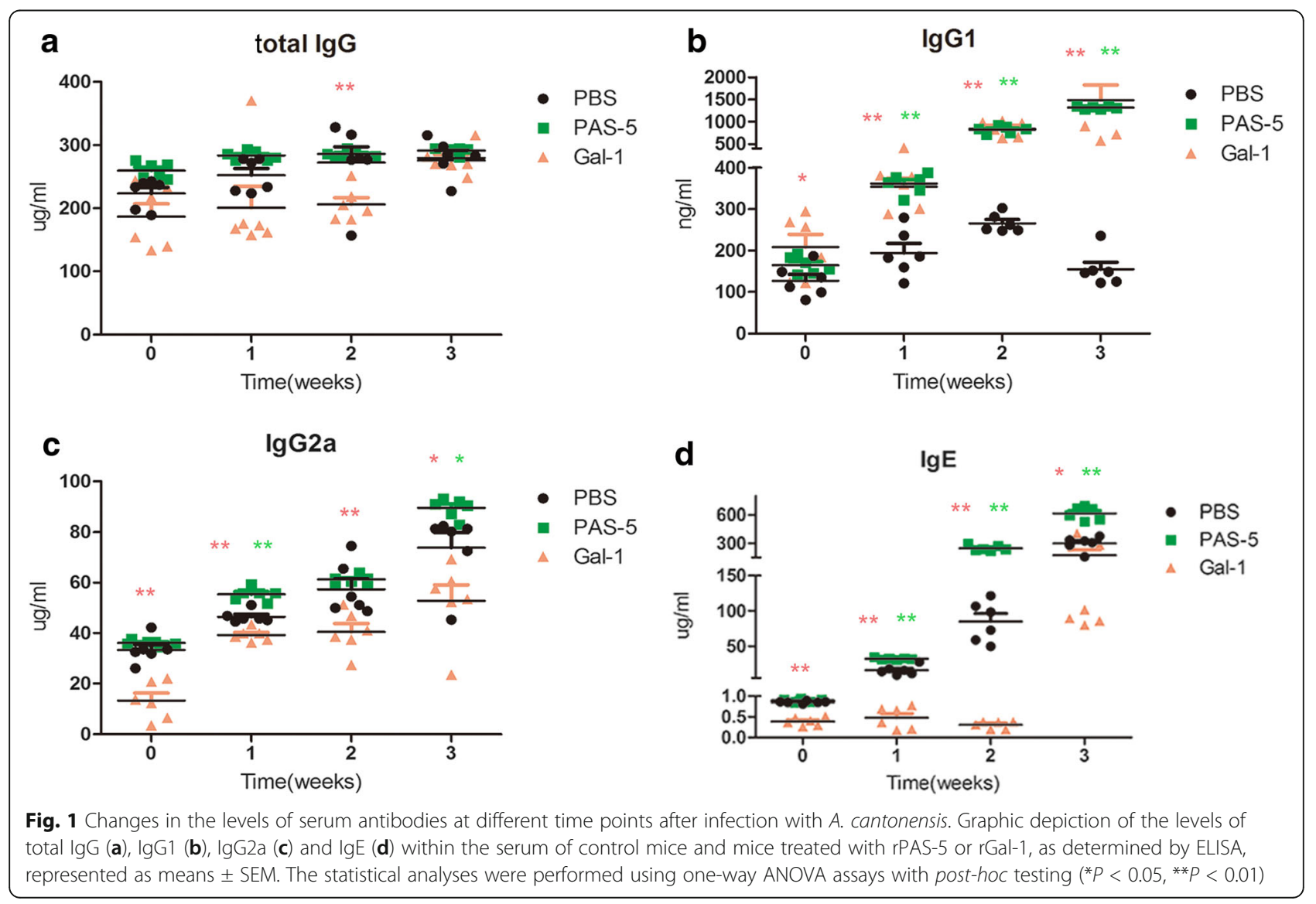




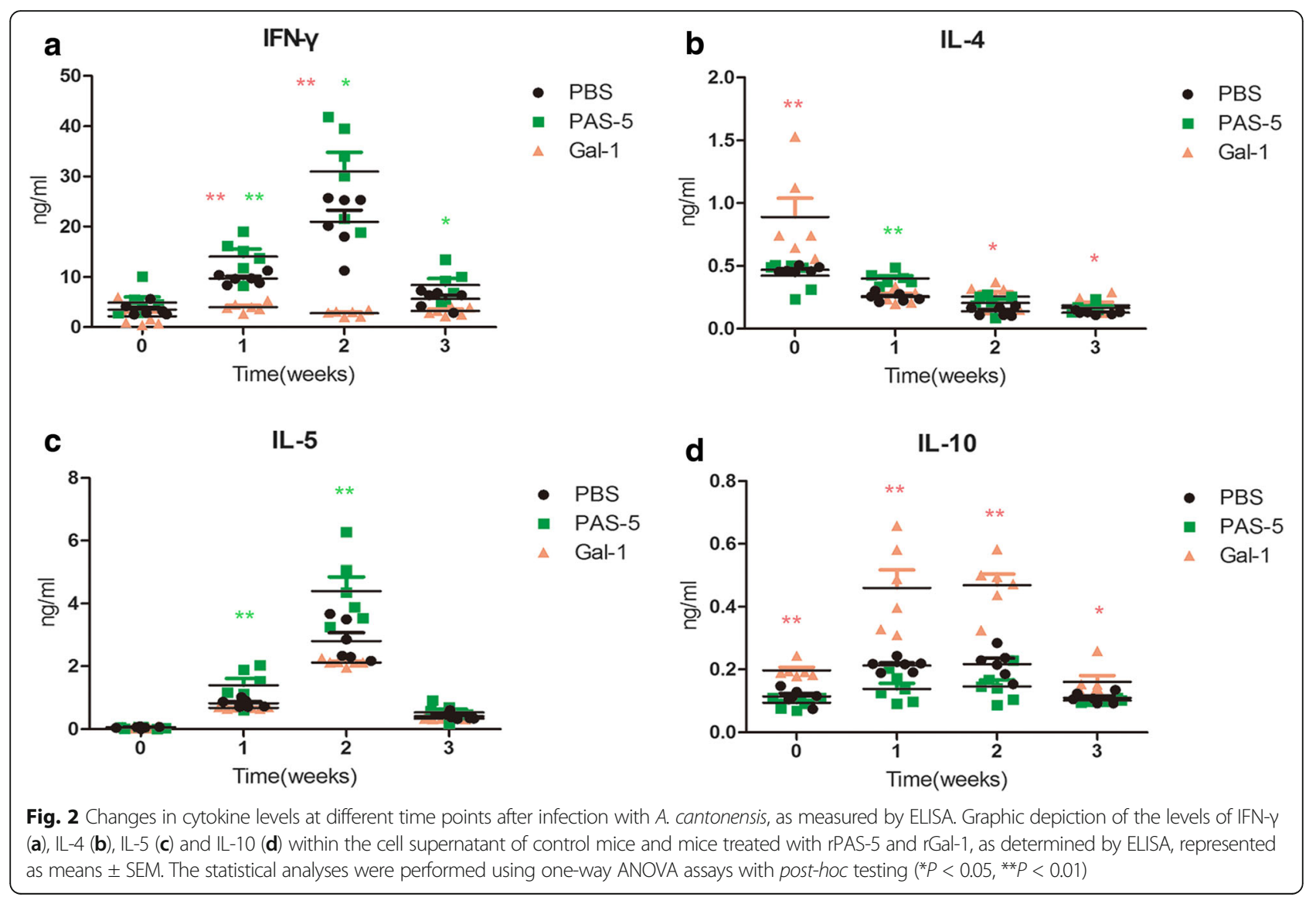

buffer, and permeabilized cells were stained using anti-FoxP3-PE antibodies (BD Biosciences) for $30 \mathrm{~min}$ on ice. Data were acquired using a FACS flow cytometer and analyzed with FlowJo software.

\section{Histopathological observation}

Specimens of brain tissue were fixed in $4 \%$ paraformaldehyde for 2 days, dehydrated with a graded series of ethanol, embedded in paraffin, sectioned, stripped, and stained with hematoxylin-eosin (H\&E). Specimens were then subjected to microscopic analysis to evaluate the levels of inflammatory cell infiltration and pathological changes and compare degrees of inflammation and damage between groups.

\section{Statistical analysis}

Data are presented as means \pm standard errors of the mean (SEM). The comparisons among 3 groups were performed using randomized block-designed ANOVA. If the difference reached a significant level, a post-hoc test was applied to investigate. All analyses were performed with SPSS 20.0 software (SPSS Statistics, Inc., Chicago, IL, USA). $P<0.05$ was considered statistically significant.

\section{Results}

PAS-5 and Gal-1 modulate the humoral immune response Compared with the control group at different times, mice treated with PAS-5 and Gal-1 respectively exhibited significantly increased serum levels of $\operatorname{IgG1}\left(F_{(2,66)}=19.003\right.$, $P<0.0001 ; F_{(3,66)}=21.917, P<0.0001$, respectively) (Fig. 1b). Treatment with PAS-5 also exhibited significantly increased serum levels of IgG2a and IgE, while Gal-1 inhibited the generation of $\operatorname{IgG} 2 \mathrm{a}\left(F_{(2,66)}=51.844\right.$, $P<0.0001 ; F_{(3,66)}=86.063, P<0.0001$, respectively), and $\operatorname{IgE}\left(F_{(2,66)}=24.143, P<0.0001 ; F_{(3,66)}=58.921\right.$, $P<0.0001$, respectively) (Fig. 1c-d). While compared with the control group, treatment with Gal-1 did not cause much difference in the levels of total IgG, except for a reduction at 2 weeks post-treatment $\left(F_{(2,66)}=16.868\right.$, $P<0.0001 ; F_{(3,66)}=7.477, P<0.0001$, respectively) (Fig. 1a).

PAS-5 and Gal-1 influence the cellular immune response After L3 infection, PAS-5-stimulated splenic cells produced high levels of IFN- $\gamma$, and cells treated with Gal-1 exhibited low levels $\left(F_{(2,} 66\right)=25.944$, $P<0.0001 ; F_{(3,66)}=24.175, P<0.0001$, respectively) (Fig. 2a). Compared with the control group, cells treated with Gal-1 resulted in an increase in the levels of 

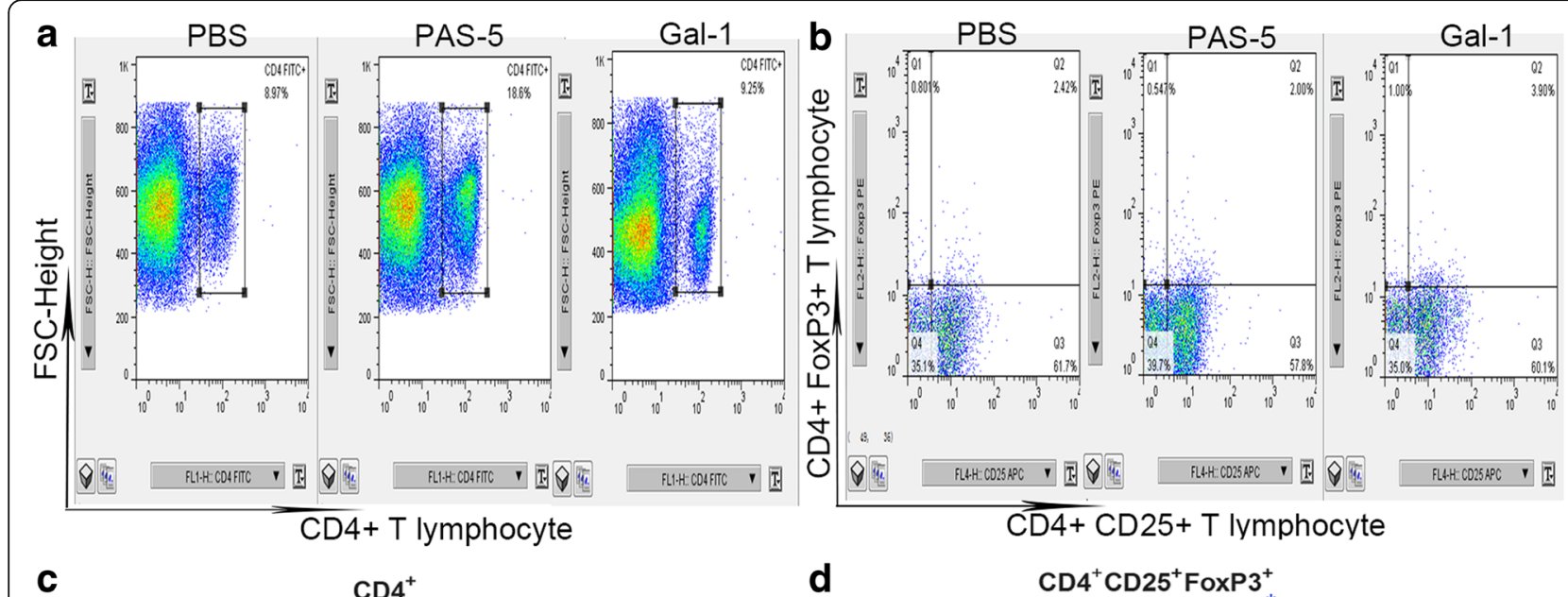

C

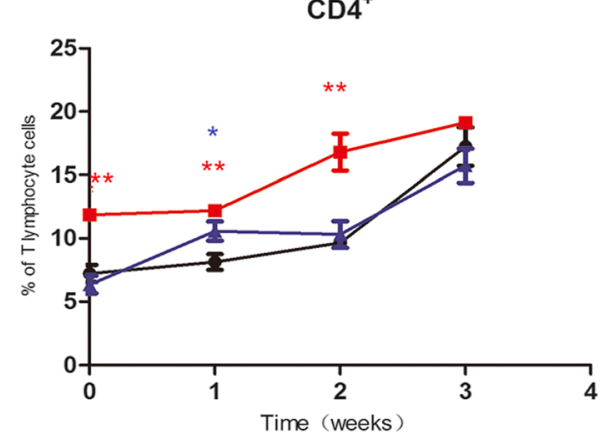

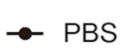

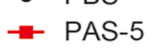

$\rightarrow$ Gal-1

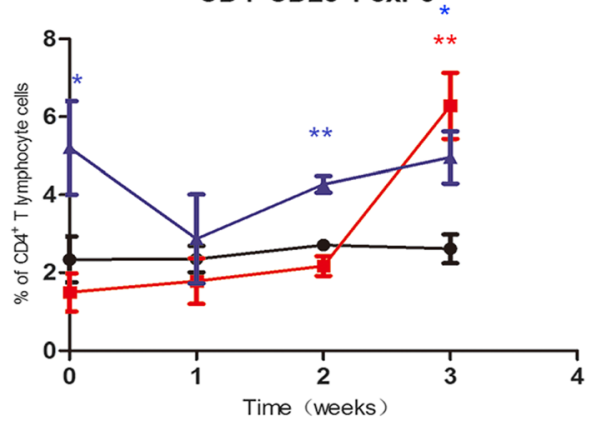

Fig. 3 Changes in the populations of immune effector cells at different time points after infection with A. cantonensis. a, b Graphic depictions of the percentages of $\mathrm{CD} 4^{+} \mathrm{T}$ cells $(\mathbf{a})$ and $\mathrm{CD} 4^{+} \mathrm{CD} 25^{+} \mathrm{FoxP} 3^{+}$Tregs (b) within the cells of control mice and mice treated with rPAS-5 and rGal- 1 at 2 weeks after infection. c, d Graphic depictions of changes in the populations of CD4 ${ }^{+} \mathrm{T}$ cells $(\mathbf{c})$ and $\mathrm{CD} 4^{+} \mathrm{CD} 25^{+} \mathrm{FoxP} 3^{+}$Tregs $(\mathbf{d})$ at different time points after L3 infection, represented as means \pm SEM. The statistical analyses were performed using one-way ANOVA assays with post-hoc testing $(* P<0.05, * * * 0.01)$

IL-4 at all chase time periods, while in PAS-5-treated cells, the levels of IL-4 was increased only at 1 week post-treatment $\left(F_{(2,66)}=5.930, P=0.004 ; F_{(3,66)}=29.769\right.$, $P<0.0001$, respectively) (Fig. 2b). PAS-5-treated cells produced high levels of IL-5, and cells treated with Gal-1 exhibited lower levels than PAS-5, but had no significant difference compared with the control $\left(F_{(2,66)}=12.828\right.$, $P<0.0001 ; F_{(3,66)}=107.637, P<0.0001$, respectively) (Fig. 2c). Meanwhile, the level of IL-10 was high in the Gal-1 group $\left(F_{(2,66)}=46.622, P<0.0001 ; F_{(3,66)}=21.660\right.$, $P<0.0001$, respectively) (Fig. 2 d).

\section{PAS-5 and Gal-1 modulate the immune response via $\mathrm{CD}^{+}{ }^{+} \mathrm{T}$ and $\mathrm{CD} 4^{+} \mathrm{CD} 25^{+}$FoxP $^{+}$Tregs}

After infection with L3, there was a progressive increase in the population of $\mathrm{CD}^{+} \mathrm{T}$ cells treated with PAS-5 (Fig. 3c). There was no significant distinction in spite of a progressive decrease in the number of $\mathrm{CD} 4^{+} \mathrm{CD} 25^{+} \mathrm{FoxP} 3^{+}$ Tregs 2 weeks after infection with L3 among the mice treated with PAS-5 $(P>0.05)$, while it was increased at 3 weeks compared with those of the control (Fig. 3d). Meanwhile, there was a significant increase in the population of
$\mathrm{CD}^{+}{ }^{+} \mathrm{CD} 25^{+} \mathrm{FoxP}^{+}$Tregs (Fig. 3d), and almost nothing had changed in the number of $\mathrm{CD}^{+} \mathrm{T}$ cells among the mice in the Gal-1 group $(P>0.05)$ (Fig. 3c).

\section{Histopathological changes}

Histopathological examination of the brains of the mice in control group detected no change at 1 week after infection, the presence of small numbers of inflammatory cells at week 2 , and expansion and hyperemia within the brain capillary, and the infiltration of large numbers of inflammatory cells at week 3 (Fig. 4). Meanwhile, only mild inflammatory changes and infiltration of small numbers of inflammatory cells were observed in Gal-1-treated mice at 2 weeks and 3 weeks post-infection, respectively (Fig. 4). Conversely, serious tissue damage was observed in the brains of PAS-5-treated mice. Specifically, some inflammatory cell infiltrating was observed 1 week after infection; subsequently, progressively larger numbers of neutrophils, lymphocytes and eosinophils were observed at 2 and 3 weeks post-infection (Fig. 4). Concurrently, the parenchyma of the brains of these mice exhibited capillary expansion, as well as infiltration of 


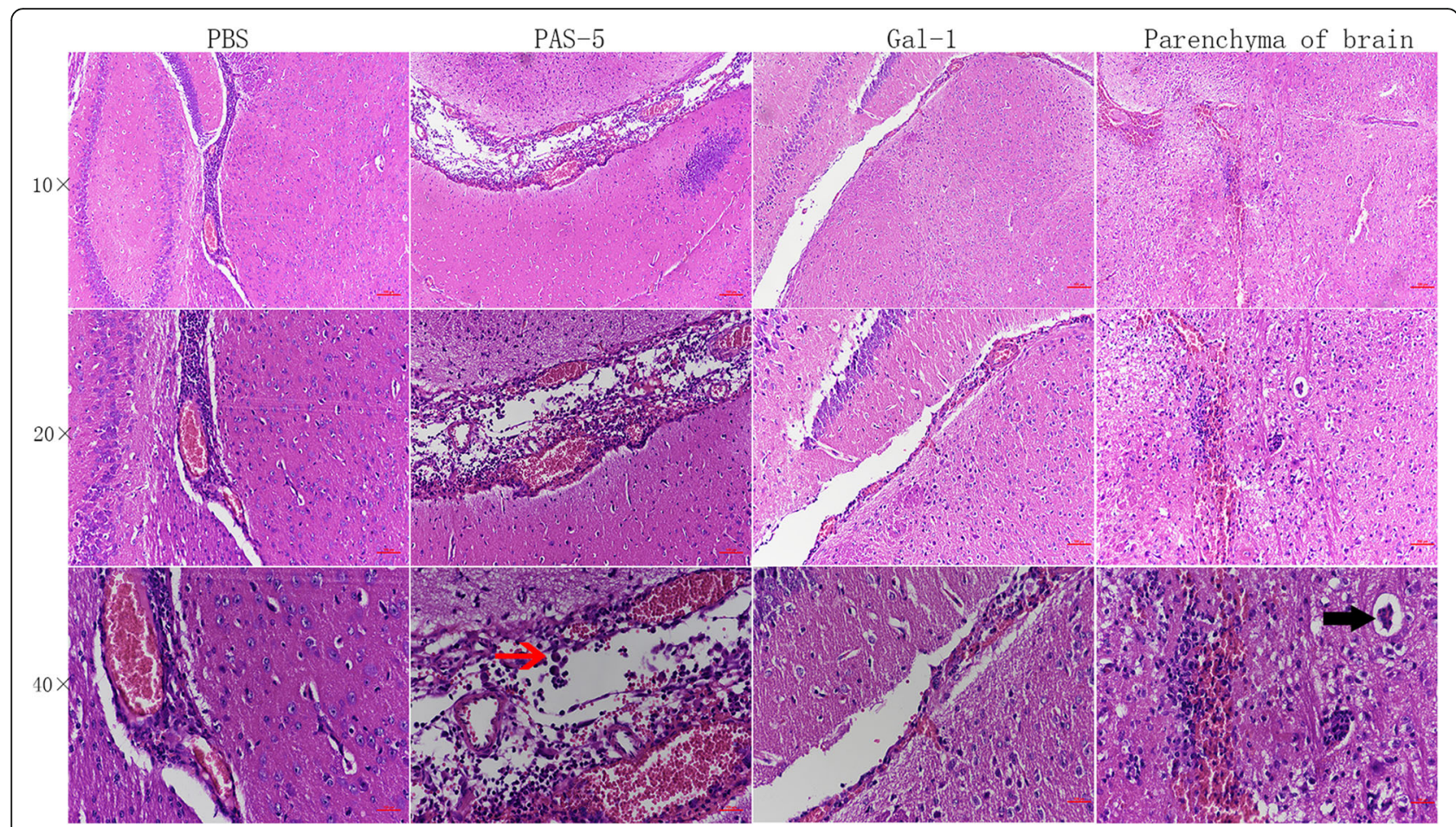

Fig. 4 Histopathological changes in the brains of mice at 3 weeks after $A$. cantonensis infection. The red arrow represents eosinophil infiltration, and the bold arrow represents perivascular cuffing in the parenchyma of the brain. Scale-bars: $100 \mu \mathrm{m}$

lymphocytes to the area surrounding these vessels, resulting in perivascular cuffing (Fig. 4).

\section{Discussion}

Although considerable research has focused on the role of proteasomal PAS-5 and Gal-1 in cancer and inflammation [15-19], the effects of these proteins on parasitic infections that affect the immune system, particularly on $A$. cantonensis infection, are not well understood. Mice and humans are both non-permissive hosts of $A$. cantonensis, and the CNS symptoms associated with angiostrongyliasis are similar [6]. Thus, mice are typically selected as appropriate animal models for studying $A$. cantonensis infection. Because angiostrongyliasis is associated with acute inflammation, we hence examined the immune responses to Gal-1 and PAS-5 within the first three weeks after infection. IgG is well known as a key component in humoral immune response. Moreover, the IgG subtypes IgG1 and IgG2a respectively indicate the Th2 and Th1 response and the levels of IgE reflect the changes of eosinophils. We thus detected these immunoglobulins here. We found that PAS-5 induced, but Gal-1 inhibited, the humoral immune response. In particular, PAS- 5 triggered both the Th1 and Th2 response, while Gal-1 inhibited the Th1 and induced the Th2 response. Previous studies showed that $A$. cantonensis infection can lead to high levels of eosinophils in both the peripheral blood and cerebrospinal fluid [3], and that eosinophils were capable of killing A. cantonensis larvae on infected mice by discharging granules [9, 20-22]. In the present study, treatment of mice with PAS-5 and Gal-1 stimulated and inhibited IgE production, respectively, thereby strengthening and weakening the host immune response after L3 infection.

IFN- $\gamma$ is a crucial cytokine for Th1 polarization [23], and our results show that $A$. cantonensis infection led to continuous increase levels of IFN- $\gamma$ until three weeks post-infection, suggesting a transfer to the Th2-type immune response through Th1. IL-4 is primarily produced by Th2 cells $[24,25]$, and the production of IFN- $\gamma$ inhibits the activation and proliferation of Th2. We observed low levels of IL-4 production during the early stage of $A$. cantonensis infection. Meanwhile, IL-5 plays an important role in the regulation of eosinophil formation, maturation, recruitment and survival $[9,20,26]$, and IL-10 could promote the down-regulation of co-stimulatory surface molecules of macrophages and inhibition of cellular proliferation, which is beneficial to parasite survival [27]. Previously, Gal-1 combined with a heavily glycosylated isoform of CD45 on the surface of undifferentiated activated Th cells was shown to facilitate the development of a molecular circuit that enhances IL-10 production and suppresses the immune response [16]. We here found that PAS-5 promoted IFN- $\gamma$ and IL-4 production, induced high levels of IL-5. Conversely, Gal-1 inhibited IFN- $\gamma$ secretion, but 
promoted IL-4 and IL-10 production. Thus, similar to our observations regarding the humoral immune response, PAS-5 and Gal-1 also induced and inhibited the cellular immune response, respectively.

PAS-5 and Gal-1 modulate the immune response via $\mathrm{CD} 4^{+} \mathrm{T}$ cells and $\mathrm{CD} 4^{+} \mathrm{CD} 25^{+} \mathrm{FoxP} 3^{+}$Tregs. T cells are comprised of two major subgroups: $\mathrm{CD} 4^{+}$helper cells and $\mathrm{CD}^{+}$cytotoxic cells. Notably, studies have shown that $\mathrm{CD} 4^{+} \mathrm{T}$ cells play a primary role in the early infection of A. cantonensis [28]. Our results showed that PAS-5 significantly promoted the production of $\mathrm{CD} 4^{+} \mathrm{T}$ cells after L3 infection, while Gal-1 had little effect on this cell type, compared with the control group. Meanwhile, $\mathrm{CD} 4{ }^{+} \mathrm{CD} 25^{+} \mathrm{FoxP}^{+}$Tregs play an important role in parasite-mediated down-regulation of the immune system [28, 29], and most helminth infections result in recruitment of Tregs [30]. Two different mechanisms have been proposed for the inhibition of Tregs during parasitic infection. The interplay between the $\mathrm{T}$ effector ligands CD80 and CD86 with cytotoxic T lymphocyte-associated protein-4 activates the transfer of immunosuppressive signals on effector $\mathrm{T}$ cells, thereby reducing the function of the latter [29]. Additionally, Tregs secrete IL-10 and TGF- $\beta$, which mediate immunosuppression [24, 30-32]. Consistent with our previous results, PAS- 5 and Gal- 1 exhibited immunoenhancing and immunosuppressing effects by inhibiting and promoting Treg secretion, respectively. It is noteworthy that PAS-5 induced high levels of Tregs at week 3 post-infection, as eosinophils were shown to release granules, as well as certain cytotoxic proteins, such as eosinophil cationic protein and eosinophil protein $\mathrm{X}$, during this time period for killing the larvae $[9,22,30]$. The release of these factors induces nerve tissue damage within the host, after which the immune response is suppressed.

$H \& E$ staining of the brain tissues of infected mice further verified the effects of PAS- 5 and Gal- 1 on the CNS. The infection of $A$. cantonensis mainly damages the ventricles of the brain and the subarachnoid cavity, and a strong immune response will contribute to the severe damage of the parenchyma of the brain $[9,30]$. Concordantly, we observed that PAS- 5 treatment resulted in severe damage to the brain, including the parenchyma, while Gal-1 caused only slight damage, compared with the control group.

\section{Conclusions}

In summary, our findings revealed that PAS- 5 and Gal- 1 have distinct effects on the induction of the immune system of mice infected with $A$. cantonensis. PAS-5 enhances both the humoral and cellular immune response through the Th1 and Th2, whereas Gal-1 inhibits the response through the Th1 pathway.

\section{Abbreviations}

2-DIGE: Two-dimensional gel electrophoresis; CNS: Central nervous system; ELISA: Enzyme-linked immunosorbent assay; FACS: Fluorescene-activated cell sorting; H\&E: Hematoxylin-eosin; L1: First-stage larvae; L3: Third-stage larvae; L4: Fourth-stage larvae; L5: Fifth-stage larvae; MS: Mass spectrometry; ORFs: Open reading frames; Tregs: Regulatory $T$ cells

\section{Acknowledgements}

We appreciate that Mr Wei-Ping Yi provided $P$. canaliculata (the intermediate host of $A$. cantonensis) used in this study. We thank Dr Li-Rong Peng (at The Geroge Washington University School of Medicine and Health Sciences) for her helpful comments on the manuscript.

\section{Funding}

This study was supported by grants from the National Natural Science Foundation of China (No. 81471234), the Science and Technology Project of Zhejiang Province of China (No. 2017C33067) and the Natural Science Foundation of Zhejiang Province of China (No. LY16H190009).

\section{Availability of data and materials}

The data supporting the conclusions of this article are provided within the article. The raw datasets used during the current study are available from the corresponding author upon reasonable request.

\section{Authors' contributions}

$\mathrm{HHC}$ and YBL conceived and designed the experiments. YLZ and HHC drafted the manuscript. YLZ, SYY, CXX and ZMJ performed the experiments. YLZ, SXM and ZYW collected and analyzed the data. HHC, YBL and LXP participated in study design, technological guidance and coordination. All authors read and approved the final manuscript.

\section{Ethics approval}

All experimental animals were treated strictly in accordance with the recommendations in the Guide for the Regulation for the Administration of Affairs Concerning Experimental Animal of the People's Republic of China. The animal protocol was approved by the Laboratory Animal Ethics Committee of Wenzhou Medical University and Laboratory Animal Center of Wenzhou Medical University (permit number: wydw2015-0134), and the care and maintenance of animals followed this institution's guidelines.

\section{Competing interests}

The authors declare that they have no competing interests.

\section{Publisher's Note}

Springer Nature remains neutral with regard to jurisdictional claims in published maps and institutional affiliations.

\section{Author details}

${ }^{1}$ Department of Parasitology, School of Basic Medical Sciences, Wenzhou Medical University, Wenzhou, Zhejiang 325035, People's Republic of China. ${ }^{2}$ Clinical Laboratory of Bethune International Peace Hospital, Shijiazhuang, Hebei 050082, People's Republic of China. ${ }^{3}$ School of the Second Clinical Medical Sciences, Wenzhou Medical University, Wenzhou, Zhejiang 325035, People's Republic of China. ${ }^{4}$ School of the First Clinical Medical Sciences, Wenzhou Medical University, Wenzhou, Zhejiang 325035, People's Republic of China.

Received: 9 January 2018 Accepted: 14 May 2018

Published online: 29 May 2018

References

1. He HL, Cheng M, Yang X, Meng JX, He A, Zheng XY, et al. Preliminary molecular characterization of the human pathogen Angiostrongylus cantonensis. BMC Mol Biol. 2009;10:97.

2. Yan BL, Sun WW, Yan LZ, Zhang LZ, Zheng $Y$, Zeng $Y Z$, et al. Structural and functional characterisation of FOXO/Acan-DAF-16 from the parasitic nematode Angiostrongylus cantonensis. Acta Trop. 2016;164:125-36.

3. Huang HC, Yao LL, Song ZM, Li XP, Hua QQ, Li Q, et al. Developmentspecific differences in the proteomics of Angiostrongylus cantonensis. PLoS One. 2013;8:e76982. 
4. Song ZM, Huang HC, Tan F, Zhang EP, Hu JW, Pan CW. Differential proteomics analysis of female and male adults of Angiostrongylus cantonensis. Exp Parasitol. 2012;131:169-74.

5. Martins YC, Tanowitz HB, Kazacos KR. Central nervous system manifestations of Angiostrongylus cantonensis infection. Acta Trop. 2015;141:46-53.

6. Feng Y, Zeng X, Li WH, Wang WC, Chen W, Ou-Yang LS, et al. The pathogenesis of optic neuritis caused by Angiostrongylus cantonensis in BALB/c mice. Parasit Vectors. 2014;7:339.

7. Yu LP, Wu XY, Wei J, Liao Q, Xu L, Luo SQ, et al. Preliminary expression profile of cytokines in brain tissue of BALB/C mice with Angiostrongy/us cantonensis infection. Parasit Vectors. 2015:8:328.

8. Morassutti AL, Perelygin A, Levert K, Lin S, Lee $Y$, Silva AJ, et al. Expression of recombinant antigenic proteins from Angiostrongylus cantonensis: a brief report. Hawaii J Med Public Health. 2013;72:58-62.

9. Morassutti AL, Graeff-Teixeira C. Interface molecules of Angiostrongylus cantonensis: their role in parasite survival and modulation of host defenses. Int J Inflamm. 2012;2012:512097.

10. Huang HC, Yao LL, Zhou ZB, Zheng LN, Pan CW. Analysis and identification of peptide epitope of the fifth stage larvae of Angiostrongylus cantonensis. Natl Med J China. 2014;94:1095-8.

11. Hong $Y$, Han HX, Peng JB, Li Y, Shi YJ, Fu ZQ, et al. Schistosoma japonicum: cloning, expression and characterization of a gene encoding the a5-subunit of the proteasome. Exp Parasitol. 2010;126:517-25.

12. Chen J, Wu SM, Zhu XQ, Huang SY. Advances on the studies of parasite proteasomes. Acta Vet Zoo Sinica. 2012:43:7-13.

13. Wang W, Wang S, Zhang H, Yuan C, Yan RF, Song XK, et al. Galectin Hcogal-m from Haemonchus contortus modulates goat monocytes and $T$ cell function in different patterns. Parasit Vectors. 2014;7:342.

14. Rabinovich GA. Galectin-1 as a potential cancer target. Brit. J Cancer. 2005; 92:1188-92.

15. Arlt A, Bauer I, Schafmayer C, Tepel J, Ster S, Brosch M, et al. Increased proteasome subunit protein expression and proteasome activity in colon cancer relate to an enhanced activation of nuclear factor E2-related factor 2 (Nrf2). Oncogene. 2009;28:3983-96.

16. Cedeno-Laurent F, Opperman M, Barthel SR, Kuchroo VK, Dimitroff CJ. Galectin-1 triggers an immunoregulatory signature in T helper cells functionally defined by IL-10 expression. J Immunol. 2012;188:3127-37.

17. Freitas Zanon C, Sonehara NM, Girol AP, Gil CD, Sonia Oliani M. Protective effects of the galectin-1 protein on in vivo and in vitro models of ocular inflammation. Mol Vis. 2015;21:1036-50.

18. Grigoreva TA, Tribulovich VG, Garabadzhiu AV, Melino G, Barlev NA. The 265 proteasome is a multifaceted target for anti-cancer therapies. Oncotarget. 2015;6:24733-49.

19. Kirschner F, Reppe K, Andresen N, Witzenrath M, Ebstein F, Kloetzel P. Proteasome $\beta 5$ i subunit deficiency affects opsonin synthesis and aggravates pneumococcal pneumonia. PLoS One. 2016;11:e153847.

20. Allen JE, Sutherland TE. Host protective roles of type 2 immunity: parasite killing and tissue repair, flip sides of the same coin. Semin Immunol. 2014; 26:329-40

21. Chen KM, Lee HH, Chou HL, Liu JY, Tsai BC, Lai SC. Upregulation of MMP-9/ TIMP-1 enzymatic system in eosinophilic meningitis caused by Angiostrongylus cantonensis. Int J Expl Pathol. 2005;86:81-9.

22. Du WY, Liao JW, Fan CK, Su KE. Combined treatment with interleukin-12 and mebendazole lessens the severity of experimental eosinophilic meningitis caused by Angiostrongylus cantonensis in ICR mice. Infect Immun. 2003;71:3947-53.

23. De Araújo CA, Perini A, Martins MA, Macedo MS, Macedo-Soares MF. PAS-1, an Ascaris suum protein, modulates allergic airway inflammation via CD8+ $\gamma \delta T C R+$ and CD4+CD25+FoxP3+ T Cells. Scand J Immunol. 2010;72:491-503.

24. Davoine F, Lacy P. Eosinophil cytokines, chemokines, and growth factors: emerging roles in immunity. Front Immunol. 2014;5:1-17.

25. Na H, Cho M, Chung Y. Regulation of Th2 cell immunity by dendritic cells. Immune Netw. 2016;16(1):12.

26. Bouchery T, Kyle R, Ronchese F, Le Gros G. The differentiation of CD4+ Thelper cell subsets in the context of helminth parasite infection. Front Immunol. 2014;5:1-13.

27. Liu YH, Han YP, Li ZY, Wei J, He HJ, Xu CZ, et al. Molecular cloning and characterization of cystatin, a cysteine protease inhibitor, from Angiostrongylus cantonensis. Parasitol Res. 2010;107:915-22.

28. Ludwig-Portugall I, Layland LE. TLRs, Treg, and B cells, an interplay of regulation during helminth infection. Front Immunol. 2012;3:1-7.
29. Kang SA, Park M, Cho MK, Park SK, Jang MS, Yang B, et al. Parasitic nematode-induced CD4+Foxp3+T cells can ameliorate allergic airway inflammation. PLoS Negl Trop Dis. 2014;8:e3410.

30. Ahn J, Kang SA, Kim D, Yu HS. Activation and recruitment of regulatory T cells via chemokine receptor activation in Trichinella spiralis-infected mice. Korean J Parasitol. 2016:54:163-71.

31. Pandiyan P, Zhu J. Origin and functions of pro-inflammatory cytokine producing Foxp3+ regulatory T cells. Cytokine. 2015;76:13-24.

32. Salazar-Castañon VH, Legorreta-Herrera M, Rodriguez-Sosa M. Helminth parasites alter protection against Plasmodium infection. Biomed Res Int. 2014:2014:913696.

\section{Ready to submit your research? Choose BMC and benefit from:}

- fast, convenient online submission

- thorough peer review by experienced researchers in your field

- rapid publication on acceptance

- support for research data, including large and complex data types

- gold Open Access which fosters wider collaboration and increased citations

- maximum visibility for your research: over $100 \mathrm{M}$ website views per year

At BMC, research is always in progress.

Learn more biomedcentral.com/submissions 